\title{
Giving Dracula the Keys to the Blood Bank? Interrogating the Fifth Crown Casino Licensing Regulatory Review
}

\author{
Linda Hancock \\ Deakin University, Australia
}

\begin{abstract}
Drawing on narrative analysis, this paper analyses the 2013 Fifth Regulatory Review of the license of an Australian casino as a case study focused on the framing and articulation of 'responsible gambling' (RG) in the Review. Part 1 sets out the policy and regulatory context for the licensing review of Melbourne's Crown Casino. Part 2 overviews the structure/content of the Review; the key messages of the Reviewers' narrative and its main recommendations. In reflecting on the Review in Part 3, analysis focuses on the investigation and recommendations regarding Responsible Gambling, which has gained recent policy priority. The analysis interrogates the Review's findings, narratives, processes and evidentiary base in relation to how it presents and assesses casino performance on RG. In doing so, it focuses on the Victorian Commission for Gambling and Liquor Regulation's Review's framing of RG; sources of evidence drawn on by the Review; an assessment of the casino's loyalty club feature 'Play Safe', as an RG measure; the Review's assessment of casino performance on RG and its Code of Conduct in particular; and the Review's framing of RG recommendations. It concludes with reflections on governance issues raised by the Review, the need for more focus on the neglected area of regulatory licensing and enforcement (OECD, 2011; 2012; OECD \& European Commission, 2009) and the need for independent regulatory reviews that address conflicts of interest on the part of both Government and the Regulator.
\end{abstract}

\section{Keywords}

Regulatory Review, regulatory inspections, casinos, responsible gambling, dangerous consumptions, electronic gaming machines

\section{Introduction}

Gambling constitutes a site of explicit state regulation as the state decides and negotiates license-tooperate conditions along with the degree of significance accorded to harmful impacts, regulatory monitoring and enforcement, harm prevention and state/operator duty of care. For many years, governments eschewed the idea of allowing casinos; or for that matter, gambling machines and casino games that were associated with Las Vegas-type organized crime and scandal. Although two of Australia's 13 casinos were opened in the 1970s (Wrest Point in Hobart in 1973 and Sky City in Darwin in 1979), it was only in the 1980s and 1990s in Australia, that casinos really took hold; as did

Copyright (C) 2013 Victoria University. This document has been published as part of the Journal of Business Systems, Governance and Ethics in both online and print formats. Educational and non-profit institutions are granted a nonexclusive licence to utilise this document in whole or in part for personal or classroom use without fee, provided that correct attribution and citation are made and this copyright statement is reproduced. Any other usage is prohibited without the express permission of the publisher. suburbanized gambling in clubs and hotels. But, casinos were treated with caution and many States have so far allowed only one to be established. In selling the idea to communities, government rhetoric has been that casinos would be regulated to prevent crime, conduct gambling honestly, prevent minors from gambling and be run with transparency, high probity standards, integrity and in the public interest. State/Territory laws and regulations reflect 
these core purposes.

State Regulators are charged with the responsibility of monitoring licensee performance and with conducting periodic reviews of casinos. They have wide powers as independent statutory authorities. While casinos may have first been seen as a means of encouraging tourism, regional development and employment, "responsible gambling" (RG) (with all its ambiguity) superseded "harm minimization" to become the new paradigm emphasized in Australia by legislators, regulators and the gambling industry since the early 2000s. As argued later, not only is the RG focus limited, but the interpretation of RG has followed conservative lines, emphasizing individual rather than industry responsibility for harms .

In contrast, conceptualizing the regulation of gambling and casinos in particular in terms of 'dangerous consumptions', has gained more emphasis nationally and internationally in countering the individualized focus of RG and the need for a public health harms prevention approach. The key message is that dangerous consumptions demand tougher regulation and stricter enforcement than more benign products. These new public health approaches challenge vested interests to 'stop the harms', with more structural reforms that limit the rapacity of products designed to entrap or addict by requiring licensed providers to exercise 'host responsibility' and a duty of care to their customers . A public health up-stream prevention of harms approach has been prompted by questions raised in two national Productivity Commission reviews of gambling in1999 and 2010; recent national Parliamentary inquiries into gambling (2012/13) and the (failed) national campaign for electronic gambling machines to be pulled back to a maximum of $\$ 1$ per button press with losses capped at $\$ 120$ per hour .

In this context, State Regulators bear a hefty responsibility to use their wide discretionary powers to regulate gambling, and casinos in particular, as potentially high-risk activities. This needs to be done in a manner that upholds public interest and good governance practices within an adaptive regulatory response that responds to and reflects research, evidence and community sentiment.

This paper focuses on the 2013 Fifth Regulatory Review of the license of an Australian casino as a case study of how a State regulator approaches and conducts a license review of one of the biggest casinos in the Southern hemisphere - Crown Casino, Melbourne (CCM). Drawing on narrative analysis, the article focuses on the framing and articulation of 'responsible gambling' in the Review. The Fifth Review was completed in August 2013 and released/ published on 14 August 2013, in the midst of the federal election campaign and barely rated a mention in the media. All five Reviews have been carried out by the Victorian gambling Regulator (previously the VCGA and VCGR); which since its launch on the 6th of February 2012, has combined gambling and liquor licensing regulation under the Victorian Commission for Gambling and Liquor Regulation (VCGLR).

Part 1 of this article sets out the policy and regulatory context for the licensing review and then outlines the governance structure of the review process and policy changes since the Fourth casino licensing Review in 2008. In Part 2, the analysis of the Fifth Review overviews the structure/content of the Review, the key messages of the Reviewers' narrative and its main recommendations. In reflecting on the Review in Part 3, analysis focuses on the investigation and recommendations regarding Responsible Gambling, which has gained policy priority since legislated amendments from 2000 and particularly from 2008 when Codes of Conduct were mandated for all licensees in Victorian clubs, hotels and the casino. The analysis interrogates the Review's findings, narratives, processes and evidentiary base in relation to how it presents and assesses casino performance on RG. In doing so, it focuses on the VCGLR Review's framing of RG; sources of evidence drawn on by the Review; the Review's assessment of Play Safe as an RG measure; the Review's assessment of casino performance 
on RG and its Code of Conduct in particular; and the framing of RG recommendations. In the final Part 4, it reflects on governance issues raised by the Review and onus on research and policy makers to focus on the relatively neglected area of regulatory licensing enforcement (OECD, 2012). Finally, regulators and governments need to ensure independence of the review process that ensures freedom from conflicts of interest.

\section{The Policy and Regulatory Context and the Casino Licensing Review Process}

\subsection{Policy context}

Australia's 13 casinos are governed by casino-specific legislation as well as legislation that applies to gambling generally. Under Australia's federal system, casino licensing is a matter for States/Territories, each of which has specific licensing and regulatory authorities set up under specific legislation (Allan Consulting, 2009). In most States/Territories casino games are mainly restricted to licensed casino premises . Casinos also typically broker numerous concessions from governments and exemptions or departures from the rules that prevail in gambling-licensed clubs and hotels. At the same time, casinos are regarded as more intensive gambling environments and are subject to stricter oversight under dedicated legislation. The larger scale of gambling in casinos compared to smaller suburban club and hotel gambling venues means that the risks associated with crime and corruption, money laundering, loan sharking and probity are higher; and that such venues are in need of greater scrutiny and tighter regulatory oversight.

In terms of community sentiment, in the 30 or so years since casino gambling was legalised in Australia, the public has stayed relatively critical of the impact of gambling; and especially electronic gambling machines. A reason for this is recognition of the harms caused by gambling and its negative impacts ; articulated clearly by two national inquiries conducted by the Productivity Commission in 1999 and 2010; a range of national Parliamentary inquiries, debates on gambling in 2012-2013 with the Gillard-Wilke Agreement and numerous State/Territory reports on the social impact of gambling.

Crown Casino is the largest casino in Australia . It is under an obligation to run a 'world-class casino' and has been subject to regulatory international benchmarking on its operational practices in this and previous Reviews (VCGA 2000, VCGA 2003, VCGR 2008, VCGLR 2013). Crown expresses its commitment to being a 'world leader in responsible gambling practices' (Crown Melbourne Limited, 2010, Crown Code, p. 2). A number of features of CCM's operations merit mention:

- Special conditions relate to its license to operate (Crown is subject to state laws and casino-specific legislation (the Casino Control Act 1991 and the Casino (Management Agreement) Act 1993) and to regulatory reviews by the combined gambling and liquor regulator, the VCGLR.

- There are regulatory and compliance challenges posed by its size and complexity of operation as an 'entertainment complex'.

- Crown Melbourne Limited is part of a larger transnational corporation (Crown Limited) with two casinos in Macau and casino interests in Canada, the US and the UK. Crown Limited Management and Board are therefore cogniscent of international differences in regulatory environments and presumably, best practice. Crown Limited's expansion into new Asia Pacific markets in Sri Lanka and the Philippines raises issues related to transnational corporate responsibility; in jurisdictions with widely recognized probity risks.

- Location of Crown Casino complex on the Southbank entertainment precinct in close proximity to the central business district, raises expectations that ease of public access to such a large venue necessitates vigilant regulatory oversight and high standards of internal operations on responsible gambling, responsible service of alcohol and security. Governments have embraced industry selfregulation via Codes of Conduct that are framed in terms of 'responsible gambling'. But how 'responsible' are casino host responsibility and responsible gambling programs 1.2 How the Review process works 
Reviews of Crown Casino Melbourne are conducted by the Regulator with the four previous Reviews conducted by the VCGR and VCGR (VCGA 1997, 2000, 2003; VCGR, 2008) and the Fifth Review conducted by the newly merged combined gambling and liquor licensing regulator, the VCGLR. It is worthy of note that the VCGLR conducts both 'extensive day-to-day regulation of casino operations and the casino operator, as well as conducting periodic casino Reviews under section 25 of the Casino Control Act' (VCGLR, 2013 p. 11). Reviews were previously three-yearly, changed to up to every five years on August 212005 . The Fifth Review is the second five-yearly Review, which includes the period 1 July 2008 to 30 June 2013. Only two Reviews within a decade poses weighty obligations on the review body, the VCGLR.

The formal requirements of the review are stipulated in Section 25 of the Casino Control Act 1991:

S 25(1) Not later than 3 years after the commencement of operations in a casino, and thereafter at intervals not exceeding 5 years, the Commission must investigate and form an opinion as to each of the following matters-

(a) whether or not the casino operator is a suitable person to continue to hold the casino licence;

(b) whether or not the casino operator is complying with this Act, the Casino

(Management Agreement) Act 1993, the Gambling Regulation Act 2003 and the regulations made under any of those Acts;

(c) in the case of the Melbourne Casino Operator, whether or not the casino operator is complying with-

(i) the transaction documents ; and

(ii) any other agreements between the Melbourne Casino Operator and the State, or a body representing the State, that impose obligations on the casino operator in relation to gaming;

(d) whether or not it is in the public interest that the casino licence should continue in force (Casino Control Act, 1991).

In terms of methodology and focus of the Fifth Review:

The VCGLR has scrutinized Crown Melbourne Limited's records, systems and outcomes in relation to its obligations concerning the conduct of casino operations; the status of the Melbourne Casino; its finances and structure; the prevention of criminal activity at the Melbourne Casino; and the welfare of patrons, including minimising the harm of problem gambling (VCGLR, 2013 p. 12).

The Review report is presented under headings: Suitability, Compliance with Obligations, Melbourne Casino Operations and Recommendations.

1.3 The shifting policy and regulatory context of the licensing Review

During the five-year period under review, a number of legislative and policy shifts have occurred in Victoria of relevance to regulatory review of the casino. The most significant of these are:

- December 1, 2008 ban on gambling whilst intoxicated (under provisions of section 81 of the Casino Control Act 1991 linked regulatory enforcement of gambling and liquor licensing laws;

- RG a priority - June 2009 Responsible Gambling Codes of Conduct mandated for implementation in clubs, hotels and Crown Casino ;

- Variations to the license including additional gaming tables licensed at Crown Casino Melbourne (CCM) in December 2009 .

- Concessions granted to Crown Casino in taxation (a high roller taxation rate), and defining 'automated table games' as table games, rather than gambling machines in 2009 . 
There were also a number of changes to the corporate interests of Crown Limited and its domestic and international growth between 1 July 2008 and 30 June 2013:

- Developments at Burswood Casino, Perth ;

- April 2009 Crown Limited bought shares in Cannery Casino Resorts, Las Vegas;

- June 2009 City of Dreams casino opened in Macau;

- April 2010 Crown Metropole Hotel opened at Southbank Melbourne.

- May 2011 Crown Limited purchased Aspinal's Club in London.

- May 2013 NSW regulator approved up to 23 percent stake in Echo Entertainment Group in NSW and Queensland regulator approves up to 24.99 percent share. Crown Limited sells its ECHO shares in May 2013.

- 2013 Crown Limited negotiating new casino licences in Sri Lanka and Philippines (VCGLR Review, 2013, p. 9).

- July 42013 the NSW Government approved Crown Limited's bid for a second Sydney casino license at the Barangaroo site to proceed to stage 3 of the development process (Nichols, 2013).

\section{Analysis of the Fifth Crown Casino Licensing Review}

\subsection{Making 'meaning' from the narrative of the Fifth licensing Review}

Narrative analysis is drawn upon in analysis of the Review. As May argues, narrative studies are frequently holistic in nature and focus on the 'sequencing of themes within narratives', focus on both form and content and present findings in the form of case studies' (May n.d.). Social scientists draw attention to the role of narrative in story-telling and in reinforcing particular power and interest relations (May, n.d; May 2008; McBeth 2005). Narrative review is multi-disciplinary and its legitimacy for the study of public/policy documents is well established (Feldman et al., 2004; May, n.d; Reissman, 2008). Narrative method draws attention to the constructed nature of how narratives are selective, how they include and exclude particular groups and interpretations, sanction certain forms of knowledge and construct social identities (De Fina \& Georgakopoulou, 2008: 382) and reflect power inequalities in how processes are legally framed and how narrative is constructed to achieve social consequences (Pedriana, 2006; Squire et al., 2008: 4). Narrative analysis is used here in the context of public reporting as a form of story telling, that is ultimately selective and reflective of certain power relations.

Narrative analysis can be used to examine how narratives both reflect and shape social contexts. How collective narratives reflect power relations whose narratives 'stick' and why, whose narratives are excluded, and what the effects of this are (May n.d.).

The purpose of narrative analysis is agreed in terms of being an interpretive research approach aimed at discovering underlying meaning and the construction of realty, where language is analysed as instrumental and related to power structures and how they work to reinforce certain structural interests. As outlined below, narrative analysis focuses on 'meaning making'.

The current popularity of narrative analysis is largely due to the 'narrative' or 'linguistic' turn in the social sciences. This has brought about a renewed interest in the role that language plays in social interaction and society: language is not neutral but rather is a means to accomplish social ends and is thus implicated in structures of power. Such an interpretive approach does not seek to analyse narratives in order to access underlying events but rather focuses on meaning making. Much of narrative analysis is based on the notion that how experiences are reconstructed and interpreted is important in itself (University of Manchester, 2013).

\subsection{The Fifth Crown Casino License Review - constructing a narrative for positive review}

The structure/content of the Review 
The Review is described by the Regulator as 'largely a compliance review' but one that is shaped by VCGLR's 'assessment of the key regulatory risks' associated with 'the changing international and local casino environment and regulatory obligations that may not align with the casino operator's commercial incentives' (VCGLR, 2013 p. 11). The Review is structured according to assessments of CCM's suitability to hold the license, compliance with statutory and contractual obligations and in terms of its Operations - focused on core gaming functions and security and surveillance. It is structured around the four key areas investigated: suitability, compliance with statutory obligations, compliance with contractual obligations, and public interest.

\section{Key messages of the Reviews' narrative}

The report explicitly sets the Review in the context of the rise of Asian gambling markets and shifts in the global casino market from the USA to Macau, Singapore and Asia, since the 2008 CCM license Review was conducted. It foreshadows significant growth, with $\mathrm{PwC}$ estimating the Asian gaming market to comprise 43 per cent of the global market by 2015 (VCGR, 2013, p. 10). The Review is sympathetic to Crown's capacity to compete internationally.

It is important that the operation and management of the Melbourne Casino keeps pace with the changing risks and commercial pressures of the international casino market. The VCGLR considers that the management team of the Crown Group is acting to meet those challenges (VCGLR, 2013, p. $10)$.

The Review is also clear that such trends and Crown's involvement in the Asian markets, which may be less well regulated, poses risks.

Equally, the VCGLR's regulation of the Melbourne Casino and casino operator must continue to evolve to ensure it is attuned to these changing risks and meeting the purposes of Victorian gambling legislation (VCGLR, 2013, p. 10).

Key risks include:

- The financial and probity risks arising from the Crown Group's significant Australian and international expansion plans;

- The increase in responsible gambling obligations and the potential for these to conflict with commercial obligations; and

- Criminals attempting to engage in illegal activities at the Melbourne Casino (VCGLR, 2013, p. 1112).

The Review is also mindful of risk factors related to Crown Ltd.'s involvement in the Macau gambling market (33 per cent investment in Melco Crown) in terms of:

- Any travel restrictions to Macau imposed by the Chinese Government;

- Further restrictions by the Chinese Government on the movement of money out of China;

- Melco Crown's current sub-concession extends until 2022 and there is no guarantee the subconcession will be extended beyond this date; and

- Relaxation of gaming laws in other regional economies that would compete with the Macau market (VCGLR, 2013, p. 71)

Even though from a financial risk point of view, there are protections of CCM: 
The Deed of Cross Guarantee binds the financial position of Crown Melbourne Limited to the other Crown Group companies and does not include any of Crown Limited's international operations, and presents a low risk to the short to medium term position of Crown Melbourne Limited (VCGLR, 2013, p. 71).

The main thrust of arguments in the early part of the Review report is to emphasize the importance of expansion into the Asia-Pacific region and Crown Group's and CCM's capacity to compete in the international VIP market.

Crown Melbourne Limited's financial performance and strength is increasingly dependent on the prosperity of the VIP market; and given its location in the world, its continued ability to attract participants to this market. Revenue and EBITDA growth is fundamental for Crown Limited to achieve its expansion plans and is highly dependent on the growth of the commission based player market (VCGLR, 2013, p. 71).

\subsection{The main recommendations pertaining to the CCM license renewal}

The VCGLR's opinion under section 25 of the Casino Control Act. Following the VCGLR's investigations and for the reasons set out in this report, the VCGLR has formed the opinion that:

a. the casino operator, Crown Melbourne Limited remains a suitable person to hold a casino licence; b. the casino operator, Crown Melbourne Limited is complying with the Casino Control Act1991, the Casino (Management Agreement) Act 1993, the Gambling Regulation Act 2003 and the regulations made under any of those Acts;

c. the casino operator, Crown Melbourne Limited is complying with the transaction documents and any other agreements between the Melbourne casino operator and the State, or a body representing the State, that impose obligations on the casino operator in relation to gaming;

d. it is in the public interest that the casino licence should continue in force (VCGLR, 2013, p. 9).

The Review makes ten recommendations with six of these in the area of Responsible Gambling. Other recommendations relate to enhancing Crown's corporate governance arrangements to implement bestpractice auditing, better display of game rules at the casino and an investigation into making them available via smart phones (VCGLR, 2013b).

The next section deals in more detail with some elements of the Review's treatment of Responsible Gambling (RG). In the words of the Chair of the Review Commissioner Robbie Kerr, 'VCGLR regulates the casino with a strong emphasis on harm minimisation and responsible gambling,' (VCGLR, 2013b). The Review therefore recognizes the increased importance of RG since the 2008 Review

\section{Responsible Gambling}

Part 3 of the Review focuses on the VCGLR framing of RG; sources of evidence drawn on by the Review; assessment of CCM's loyalty program Play Safe Limits; the Review's assessment of CCMs Code of Conduct performance; and the Review's RG recommendations.

\subsection{VCGLR Review's framing of "RG";}

CCM approach to RG is focused on a mix of mandated and voluntary measures that are consistently described by both the Review and by CCM in its submission (Crown Melbourne Limited, 2012) as including: 
- compliance with state government requirements on signage (including information, clocks on machines etc.)

- voluntary establishment of the Customer Support Centre (established as a voluntary commitment in 2002) and more recently its Chaplaincy Support Service

- CCM's establishment of a Responsible Gambling Committee

- restriction of credit to international players with verified identity as a condition of participation in commission based play arrangements (VCGLR, 2013 p. 91)

- implementation of a self-exclusion process

- maintenance of a Responsible Gaming Contact Register to record complaints about a patron's gambling by family or friends (VCGLR, 2013, p. 92)

- the Play Safe Limits program which enables Signature (loyalty) club members to voluntarily set time or spend limits for each session prior to playing the machines on a daily or annual basis (VCGLR, 2013, p. 90). This is described by CCM as its 'voluntary pre-commitment program' (Crown Melborne Limited, 2012).

- Player activity statements are provided to Crown Signature Club members in accordance with requirements related to loyalty programs

- CCM's obligations to implement a Responsible Gambling Code of Conduct under 2008 amendments to the Gambling Regulation Act 2003.

From a regulatory perspective, RG was approved as a focus for the Regulator's Reviews of CCM in the Third Triennial Review (VCGA, 2003) following legal and regulatory policy changes to governing legislation. In its briefing to Hanks QC the VCGA (below) noted the change in legislative priorities with the dropping of 'promoting tourism, employment and economic development generally in the State' from S 140 of the Casino Control Act and the fostering of RG in casinos as a priority (a policy re-direction introduced in 2000 by the Bracks government took over from the previous Kennett Liberal government):

(a) ensuring that the management and operation of casinos remains free from criminal influence or exploitation; and

(b) ensuring that gaming and betting in casinos is conducted honestly; and

promoting tourism, employment and economic development generally in the State.

fostering responsible gambling in casinos in order to-

(i) minimise harm caused by problem gambling; and

(ii) accommodate those who gamble without harming themselves or others (VCGA, 2003, p. 33-34, policy briefing cited by Hanks QC).

Under the Third Triennial Review, 'Responsible gambling was defined as 'the social and personal damage that may be attributable to gambling (VCGA, 2003, p. 5) and was one of the terms of reference for the Operational Compliance Subcommittee, including investigating Crown's performance in delivering responsible gambling in the casino and Crown's responsible gambling management, security and service and surveillance' (Hancock, 2011, p. 129).

The Fourth 2008 Review placed emphasis on an investigation of 'gaming activities' under which it included 'responsible gambling obligations'. In terms of its key focus on whether or not Crown Casino had breached its statutory obligations, the Fourth Review states:

The Commission recognises that the comprehensive approach by Crown Melbourne to responsible gambling (while there is still room for improvement) makes Crown Melbourne a world leader.

The Commission examined Crown Melbourne's compliance with relevant harm 
minimisation (responsible gambling) legislation and its corporate approach to the provision of problem gambling services, such as counselling services, patron

exclusion processes, the provision of problem gambling services information and how Crown Melbourne informs itself of problem gambling research.

The examination confirmed that Crown Melbourne has not breached its statutory

obligations in relation to responsible gambling and Crown Melbourne's participation in responsible gambling working parties and its establishment of complementary programs indicate a commitment to deliver its gaming products in a responsible manner (VCGR, 2008, P. 21).

In its Fifth Review VCGLR (2013, p. 81) sees RG as 'an important element' of the CCM operations, and makes reference to the way that '( $\mathrm{g}$ )ood responsible gambling practices can ameliorate or prevent some of the harms caused by problem gambling. They also demonstrate good management and show a commitment to patron welfare.'. They also demonstrate good management and show a commitment to patron welfare' and the increasing importance of RG as reflected in 'the growing list of obligations within the Casino Control Act and the Gambling Regulation Act, designed to protect gamblers from harm' (VCGLR, 2013, p 81).

However, compared to previous Reviews, the Fifth demonstrates a shift in the way RG is framed. In terms of its evaluation of CCM performance, the Review frames RG in individual terms rather than in the broader remit of operator responsibility, beginning its assessment of CCM performance on RG with a reference to Crown's framing of RG, which also reinforces an individual rather than an operator responsibility focus.

As Crown Melbourne Limited notes in its Responsible Gambling Code of Conduct, gaming is enjoyed by the vast majority of their customers, but some people have difficulties with gambling responsibly and this may cause them, and those around them, harm (VCGLR, 2013, p. 81).

The Review cites a definition of RG obtained from The Victorian Responsible Gambling Foundation and defines responsible gambling as 'gambling in a way that is controlled, is within the gambler's financial means and does not interfere with the gambler's life or the lives of those around them. As shown below, this definition has framed the subsequent Review.

This definition informed the way the VCGLR conducted its investigations and the way the issues were approached. In particular, the definition provided context when considering the processes and procedures Crown Melbourne Limited uses to meet its responsible gambling obligations (VCGLR, 2013, p. 82).

Curiously, the definition used above does not appear from searches of Foundation publications and the VCGLR Review does not draw on the major document published by the Responsible Gambling Foundation in its Guide to Responsible Gambling, which differentiates what RG means for individuals and providers. According to the Foundation:

For individuals it means:

- they may gamble for pleasure and entertainment but are aware of their likelihood of losing, and understand the associated risks

- they exercise control over their gambling activity

- responsible gambling occurs in balance with other activities in their lives and is not causing problems or harm for themselves or others

For providers it requires: 
- shared responsibility for generating awareness of the risks associated with gambling

- creating and promoting environments that prevent or minimise problem gambling

- and being responsive to community concerns around gambling (Responsible Gambling Foundation n.d. p. 8)

Notably, the elements of importance to providers including host responsibility to prevent harms, are not emphasized in the guiding definition adopted by the VCGLR Review; but rather a reverse-onus on the patron or customer, urged to control their gambling .

Crown's Review submission outlines its approach to RG:

Crown has been committed to Responsible Service of Gaming (RSG) since inception. Crown has led the way in RSG initiatives, including Crown's voluntary

pre-commitment program (in place since 2003) and its unique array of available

services comprising dedicated and specially trained staff of RGLOs, RGPs and

Chaplaincy support, all available from its Responsible Gaming Support Centre

(RGSC) 24 hours a day, 7 days a week. Crown's initiatives place it at the forefront

in Australia and arguably the world, in relation to RSG. Crown Signature Club members have access to a kiosk facility to view their Player Activity Statements (PAS). Members can sign up for Crown's voluntary precommitment program (named Play Safe Limits), where they can voluntarily nominate predetermined time and loss limits (Crown Melbourne Limited (Crown Melbourne Limited), 2012, p. $7-8)$.

Crown frames its submission in terms of 'responsible service of gaming (RSG)'. Such use of language focuses on the more benign term 'gaming' rather than 'gambling' and is not a term usually associated with the framing of Responsible Gambling (RG). Two elements of this phraseology merit comment. Use of the word 'gaming' is ambiguous as it may be taken to encompass gaming that is not gambling, i.e., that is not conducted for money and is purely for fun. Its terminology 'responsible service of gaming' [ital added] delimits its remit to that of a provider of a service implying the consumer has certain opt-in choices, but where its own obligation to provide a safe gambling environment and provision of safe gambling products is not acknowledged. Crown Melbourne has a 'Senior Manager Responsible Gaming' and from 2010 Crown Ltd. set up a Responsible Gaming Committee .

In accordance with its Charter, the Committee:

- Monitors and reviews the operation and effectiveness of responsible gambling programs;

- Recommends responsible gambling policiesand procedures;

- Promotes improved responsible gambling practices; and

- Promotes awareness of responsible gambling (VCGLR, 2013, p. 85).

The use of language is important in promoting a normalization of gambling by eliding it into 'gaming'. Notably, the term 'Responsible service of gaming' is used only once in the two-volume Productivity Commission $(2010,2010,12.35)$ report and that reference is to training programs in responsible service of gaming for hotels, clubs and casinos citing the submission of the gambling industry peak body, the Australasian Gaming Council [previously the Australian Gambling Council]. This would imply the industry is keen to promote a change in terminology that is in its own interest and has had some element of success with the term being embedded in section 58A of the Casino Control Act in reference to staff training in an approved Responsible Service of Gaming Course and the Review has picked up the term in its heading 'Responsible service of gaming training'. 


\subsection{Sources of evidence drawn on by the Review, in addition to its own information;}

Data relied on by the Review included Crown Melbourne Limited's (2012) submission to the VCGLR and responses to questions, data from CCM relating to RG procedures and RG surveys it undertook, presentations from Crown and a tour of the RG Support Centre, Interviews with Chair of Crown Limited's Responsible Gaming Committee, agendas and minutes, Crown Melbourne Limited and Crown Limited committees and the annual reviews conducted by Crown Melbourne Limited of its Responsible Gambling Code of Conduct, consultations with gambling experts and a third party round table including Gambler's Help counselors, research material from the Victorian Responsible Gambling Foundation; responsible gambling initiatives at other casinos; and international gambling regulators (VCGLR, 2013, p. 81-82).

In the absence of a formal hearings and longer more inviting submission process, for example, in response to a discussion paper or draft report (which were absent from the recent review process), the level of detail on whom was consulted, and the thoroughness of the research and consultation process is lacking Apart from the public advertisement at the start of a 9-month process, giving a six week window to make a submission it is not surprising that the only submission was that of Crown Melbourne Limited (and that a similar result pertained to all five reviews so far). This should raise questions about the Regulator's community engagement strategy on casino licensing Reviews and the lack transparency on which experts and third parties were consulted and to what extent. In terms of the Review drawing on information from within the Regulator, there is a lack of insight into its findings drawing on unpublished data from day-to-day monitoring of the casino and matters raised by Inspectors and others during the five-year Review period. The Review brings to light the lack of transparency of detailed reportage of the inspectorial and enforcement activities of the Regulator.

\subsection{Assessment of Play Safe as RG}

Play Safe, introduced in June 2003, lets members of Crown's Signature club voluntarily set time and spend limits for each session prior to playing EGMs (VCGLR, 2013, p. 90). PlaySafe Limits is also the conduit though which players can opt to play machines in "restricted areas", that are exempt from state government limits on spin rate, note acceptor limits, spin rates, bet limits and payout by check that apply to other gambling machines in Crown and to machines in club and hotel venues in Victoria. (VCGLR, 2013, p. 90). Once the time or spend limit is reached the 'machine emits an audible tone and displays a written message, explaining that the patron can no longer accrue membership points for the Signature Club' (VCGLR, 2013, p. 90) . Consistent with their mutual emphasis on the individual control of gambling, the Review notes, 'Play Safe Limits provide an opportunity for patrons to approach Crown Melbourne Limited staff for assistance, if required' (VCGLR, 2013, p. 91).

It would appear that CCM continue to record patron play data session and spend that is automatically recorded, so they would still be aware of whom the big EGM spenders are. The fact that the Operator (CCM) does not intervene or shut off play once the limit is reached, considerably weakens the efficacy of the program as a problem gambling risk management mechanism. The Review presents data supplied by CCM showing that the Play Safe Limits program has had a significant increase from approximately 12,500 members in 2010 using it increasing to approximately 37,000 in 2012, but says Crown does not know the reasons for the increase and this is not the subject of Review investigation (VCGLR, 2013, p. 90). The Review does not interrogate a matter of some concern that up to 1000 of CCM's 2,500 electronic gambling machines are approved for virtually unrestricted gambling that is not subject to state limits designed to protect consumers and that the facility of $\$ 100$ bank note acceptors and exemption from pay-out by cheque on these machines, renders them at risk of use for money laundering purposes.

The Review recognizes money laundering as a risk, however the detail of the Review does not adequately examine the extent to which opportunities (such as unregulated EGMs played under Play 
Safe exemptions) that exist for such activities are being used nor does it explore better means of preventing such activities by for example, not allowing such exemptions. This represents a serious public interest gap in the Review's investigation. Of course, that such machines can be played with perhaps no player tracking is also a concern that is not addressed by the Review's recommendation that Crown trial player tracking of Signature Club members in VIP rooms .

\subsection{The Review's assessment of CCM's Code of Conduct performance}

From 1 June 2009, all gambling licensees in clubs, hotels and the Melbourne Casino are required to implement a Responsible Gambling Code of Conduct, as required of CCM under section 69 of the Casino Control Act 1991. Codes need to comply with the requirements set out in Division 2 of Part 6 of the Gambling Regulation Act, need approval from the Regulator and must conform to Ministerial Guidelines. The Crown Casino RG Code as it will be referred to here, has had three amendments approved by the Regulator.

The latest amendment - not dated but 'recent' (VCGLR, 2013, p. 85), modified 'the observable signs of distress' on which staff receive training to guide their implementation of the Code. The amendment as said to draw in particular on Identifying Problem Gamblers in Gambling Venues: Final Report (Delfabbro et al. 2007); and Current Issues Related to Identifying the Problem Gambler in the Gambling Venue (Australian Gaming Council, 2002). The Review also made the observation that 'Crown Melbourne Limited's Responsible Gambling Code of Conduct and general responsible gambling intervention framework relies heavily on staff identifying observable signs of distress' (VCGLR, 2013, p. 85). Below table 1 lists changes to the list of observable signs of distress in Crown Melbourne Limited's Responsible Gambling Code of Conduct.

Table 1. The Review's outline of Crown Melbourne's Amended Code of Conduct

List of observable signs of distress

PRIOR to amendment

- Either gambling every day or finding it difficult to stop gambling

- Gambling for extended periods without a break

- Avoiding contact while gambling

- Communicating very little with anyone else

- Barely reacting to events going on around them

- Displaying aggressive, antisocial or emotional behaviour while gambling

- Making requests to borrow money from staff or other customers or continuing to gamble with the proceeds of large wins

List of observable signs of distress

FOLLOWING amendment

- Self disclosure of a problem with gambling or problems related to gambling

- Request to self-exclude

- Distorted and irrational attitudes about gambling

- Barely reacting to surrounding events

- Intolerance to losing, displayed as bad temper or distress

- Significant variation in mood during a gambling session

- Children left unattended whilst parent/guardian gambles 
- Regular complaints to staff about losing or blaming the venue/staff for their losses

- Requests to borrow money for gambling

- Showing a pattern of gambling for long periods without a break

- Progressive reduction of self-care e.g. appearing unkempt or fatigued

- Requests for assistance from family and/ or friends concerned about aindividual's gambling behaviour (VCGLR, 2013, p. 87; Table 5 [bold added]).

While the Review emphasizes Crown's reliance on ' an accepted and researched premise that observable signs are the best indicators of potential problem gambling behaviours', six of the signs in the amended Code (shown in bold above) rely on a communication from the patron or family/friends rather than externally observable signs. This is consistent with the CCM promotion of the individual control model discussed above and relies on proactive behaviour on the part of the patron (that involves some recognition of gambling-related problems and necessitating some interaction with staff); rather than the observable signs cited in the research upon which the amendments are purportedly based (that of Delfabbro, 2007 and Australian Gambling Council, 2002; shown in information box 4 [VCGLR, 2013, p. 86]).

Here we have a situation where the Reviewer is understandably uncritical of the content of a Code, which it has already previously approved. In Box 6 (VCGLR, 2013, p. 98), it refers to much more specific signs in the New Zealand code but does not undertake a comparative analysis of the amended code against what might be considered best practice and against which CCM's latest Code of Conduct compares very poorly.

Is there enforcement of the Code of Conduct?

To ensure its employees can make an assessment, CCM has developed a Senior Manager Responsible Service of Gaming training session for managers and senior floor staff as an additional measure to the mandatory Responsible Service of Gaming course that all gaming staff must complete. If a patron displays observable signs of distress, Crown Melbourne Limited staff are instructed to contact a Responsible Gaming Liaison Officer or the Responsible Gaming Support Centre. There appears to be no assessment of whether this system is implemented effectively.

The crucial question about codes is whether or not they are enforced (OECD, 2012; Monk, 2012). The Crown Casino Code of Conduct comes under state provisions making codes mandatory (but freeform) and approved by the Regulator under general Ministerial Direction (Victorian Commission for Gambling Regulation [VCGR], 2009). Under this self-regulatory system, Crown Casino is reliant on its workers to know its Code of Conduct and to act as the first link in the chain to effectively identify problem gamblers and initiate interventions, albeit in an 'upward report to supervisor' model .

Notably, the Review relies on evidence provided by CCM in its submission, which it does not subject to independent review. For such a significant review and only the second in a decade, the lack of research specifically conducted for the review is notable. On the matter of staff training on RG, the Review is descriptive of routine processes, but has not undertaken its own analysis of the effectiveness of training. It draws extensively on Crown Melbourne Limited's (2012) submission for the evidence on which it draws. On this basis it concludes:

Crown Melbourne Limited conducts a formal review for all staff twice a year. As part of this review, Crown Melbourne Limited evaluates its staff's adherence to their Responsible Gambling Code of Conduct. Crown Melbourne Limited has advised the VCGLR that since 1 January 2008, the performance management system has raised no issues in relation to staff adherence to the Responsible Gambling Code of Conduct (VCGR, 2013, p. 85). 
The Review cites evidence from internal Crown Casino surveys of customers and staff in relation to the Code, but there is no disclosure of the questions asked, the number of respondents or whether the survey was anonymous. In any event, the survey does not specifically test staff awareness or implementation of the specific 'signs of distress'. The questions do not test application of RG or the Code or the efficacy of current practices.

The Review does not engage with counter evidence (Hancock, 2011), where data from 225 Crown Casino employees interviewed in their own time via private contacts from the Union, give rare insight into problems with the way the Code of Conduct works in practice. Interviewing casino employees gives valuable insight into what actually happens 'on the floor', how the Code of Conduct 'works' and how self-regulation works in practice. Staff reported that financial imperatives often led to compromise on implementation of the Code and that the Code was not enforced very well.

That study also tested casino employees' understanding and implementation of the Crown Code of Conduct [prior to amendment in table 1 above, when the Code had ninesigns of problem gambling (shown below). It is also noted that the Code compares unfavourably with the 32 signs of problem gambling used in New Zealand and the 20 signs used in Switzerland (Hancock, 2011); and could be regarded as minimal in terms of best practice.

In the study by Hancock (2011), staff indicated inadequate knowledge of the codes they are meant to be enforcing. Based on the 'signs of distress' of the code prior to amendment (Table 2), questions to staff about awareness of code items showed some concerning low levels of awareness of the Code they were meant to be implementing.

Table 2. Crown Casino staff awareness of RG Code 'signs of distress'

Low awareness levels of problem gambling signs by staff

- $\quad 55.6 \%$ 'communicating very little with anyone else'

- $\quad 59.3 \%$ 'continuing to gamble with the proceeds of large wins'

- $\quad 61.2 \%$ 'avoiding contact with others while gambling'

Mid-level awareness

- $\quad 72.9 \%$ 'barely reacting to events going on around them'

- $\quad 76.2 \%$ 'gambling every day'

- $\quad 80.8 \%$ 'gambling for extended periods without a break'

Higher level awareness

- $\quad 89.3 \%$ 'displaying aggressive, antisocial or emotional behaviour while gambling'

- $\quad 92.5 \%$ 'finding it difficult to stop gambling' and

- $\quad 92.5 \%$ 'making requests to borrow money from staff or other customers'. (Hancock, 2011, p.

79)

Consistent with the research literature on the ability of gaming venue staff to identify problem gambling behaviours (Delfabbro 2007, 2008), almost 70 percent (69.1\%) of casino staff in this study said they 'find it easy to identify who the problem gamblers are' (and an additional $13.5 \%$ were unsure). However for Codes of Conduct to be effective, they need to identify the right signs and they need to be consistently implemented.

Staff are trained to report patrons exhibiting signs of problem gambling to supervisors. Apart from the fact that knowledge of some of these signs is wanting, the 'upward report-to-supervisor' process is ambiguous and results in low rates of floor staff interventions in problem gambling - because many staff do not follow the Code of Conduct; and some do not see the point as little comes from their notifications. Asked why they do not intervene, 71 percent said "it's not my place to do it"; 25 percent said "I'm not trained to do it", Twenty-five percent said "I'm told not to" and twelve percent 
said "I am told to wait for a customer to ask for assistance". This is despite research cited above, confirming that venue staff can reliably identify problem gamblers on the basis of visual and behavioural cues. Almost 70\% (69.1\%) of casino staff in this study said they "find it easy to identify who the problem gamblers are". In the same study:

- 65.3 percent of casino employee interviewees say they do not advise customers to take regular breaks in play.

- 55.3 percent say they would not intervene when customers are in a distressed state while they are playing; and

- 81.2 percent say they do not approach people they think are having problems with their gambling.

- $17.6 \%$-answered YES to the statement: "I sometimes feel under pressured by management to keep people gambling" (Hancock, 2011, p. 83).

Commenting on these findings, Canadian Alberta Gambling Research Institute Prof. Garry Smith (2012) states: "The "regulatory failure" verdict stems from the wilful blindness exhibited by both Crown Casino senior management and Victoria regulators. Management, for fostering a corporate culture where profit maximization trumps other considerations, including following the Responsible Gambling Code of Conduct; and regulators, whose 'light touch' oversight allows the Code's tenets to be violated without serious consequence, are the enablers...' and refers to 'poorly defined outcomes, deficient information gathering, monitoring, and assessment procedures, and the superficial 'light touch' manner adopted by government regulators'.

Clearly, Codes of Conduct need both the right 'signs' and a culture where risk and problems from gambling are seen as preventable and where gambling environments are operated with enforcement of host responsibility and a culture that prioritizes responsibility to prevent harms before commercial goals.

\subsection{The Review's RG Recommendations}

The Review found positively on RG: 'that Crown Melbourne Limited generally has robust and detailed systems and processes for dealing with responsible gambling issues and that since 2008, it has generally complied with its obligations under the legislation (VCGLR, 2013, p. 93). However a number of its recommendations were directed at RG matters.

The Review observed that for better Board oversight and management of RG issues, governance structures need improvement to address the fact there are no formal links between the Crown Board and the Crown Limited Responsible Gambling Committee (VCGLR, 2013, p. 93-94). As the Review noted: 'there is no formal consideration of responsible gambling issues by the Crown Melbourne Limited Board at its meetings' (VCGLR, 2013, p. 94). It also recommended trial of player tracking using well-established methods used in Canada and approved for use under Auckland Casino's licensing conditions by the New Zealand Regulator. The Review was critical of a paper by Schellinck and Schrans (2011) on grounds it was not peer reviewed (although it appeared in a peer reviewed journal).

With player tracking analysis now a well-developed technique for interventions on both risk and harm, the 18-month time frame for a trial is over-generous (given that player data can be retrospectively dropped into such analysis). The lack of specification on how the program would run and be audited, leaves central questions unaddressed. For example, it does not address whether patrons found to be experiencing problems would be excluded from gambling, in a manner analogous to the provision on not serving intoxicated patrons under liquor licensing laws. In respect of preventing minors entering the casino or for detecting self-excluded patrons, the recommendation for face recognition technology is long overdue and the 12 month implementation timeframe and absence of any requirement for independent evaluation, is overly generous to the Operator. 


\section{Critiquing the Review}

\subsection{Critiquing excusatory narratives}

The focus on the competitive Asian gambling market as a key driver of Crown's growth and the interpretation of the local market as 'mature' (implying it lacks importance), can be read as directing attention to the role of the Review in supporting measures that enable Crown's growth based on growing international markets. This directs attention to the growing and increasingly competitive international VIP market (both within Australian casinos and internationally). This positions the expenditure on Perth and Melbourne's Crown Casino refurbishments withn the context of international tourism and growth, rather than the impact of casino operations on local communities. The Review focus is on the International VIP Asian market to the exclusion of analysis of the segmented markets (for example, youth, senior citizens, migrant communities), that contribute to CCM's overall financial performance. In addition to the high roller, private suites and select VIP rooms, the main gaming floor attracts local Asian communities to table games, senior citizens in particular, to electronic gambling machines and young males, particularly from construction and trade industries to sports bars, table games and poker. Local patrons at lower level restricted areas (such as Teak Room) requiring loyalty club entry off the main floor, also contribute significantly to revenue and are also matters for 'responsible gambling' and host responsibility focus.

Questions raised by the review is whether the Commission uses its powers adequately to formally propose conditions upon the licensee or to invoke sanctions is at issue. Under the Casino Control Act 1991, the Regulator has wide powers to amend the conditions of a licence under Section 16 (Amendment of conditions) the Regulator has the power to cancel suspend or vary the license and impose fines up to $\$ 1$ million (Section 20), to give a casino operator written direction that relates to the conduct, supervision or control of operations in the casino (Section 23) and to report its findings to the Minister and 'take whatever action it considers appropriate in the light of its findings' (Section $26(2))$.

The Regulator thus has wide on-going powers of discretion that can be invoked at any time during casino monitoring and not only at the periodic (five-yearly) Reviews. As noted by the Victorian Responsible Gambling Foundation ‘

The Gambling Regulation Act 2003 is the main piece of legislation governing gambling in Victoria. It empowers the Victorian Commission for Gambling and Liquor Regulation to set standards for venues and machines, to licence companies and venues to provide gambling and to lay down codes of conduct and self exclusion tools. Regulations have a role to play in minimizing harm from gambling and promoting responsible gambling (RGF, n.d. p. 10).

Interrogating regulatory inspections, the Review relied on the Regulator's own monitoring data and activities/data generated by the Review itself and resourced from within the VCGLR over a nine month period. As previously discussed, narrative review is concerned with both inclusions and exclusions. The Review gives very little insight into the data it routinely collects or the issues it may from time to time take up with CCM . In terms of the Regulator's monitoring, the Fourth Review disclosed that:

Commission inspectors are stationed onsite 24 hours a day to monitor gaming activity and Crown Melbourne's compliance with its regulatory obligations. The Commission conducts weekly meetings where any issues can be raised and matters addressed as they arise. A Monthly Report of Casino Activities is provided to the Commission, which acts on any issues as they become known (VCGA, 2008, p.2).

Much of the regulatory focus of Casino Inspectors appears to focus on exclusion of minors, gambling machine payouts, operational probity of games and tax collection probity, rather than on licensee RG 
and host responsibility obligations. From the available data in the Review and VCGLR annual reports, the formal sanctions resulting from casino inspectors' activities do not seem to draw on the more serious end of their wide-ranging powers that include criminal prosecutions, written warnings, and disciplinary action.

The lack of research on regulatory enforcement has been noted internationally (Monk 2012; Blanc 2012). A 2012 OECD workshop report noted:

(C)onclusions of the workshop confirmed that regulatory enforcement and inspections is a relatively new and underestimated element of regulatory policy that has been gaining importance recently. Only a few OECD countries have introduced significant cross-cutting reforms in this area, despite the fact that there are many opportunities to improve effectiveness and efficiency of inspections and therefore regulatory efficiency through better targeting of inspections and making enforcement more outcomeoriented (OECD, 2012 n.p.).

Inspectors 'are often experts without a set of common competencies or frameworks for inspection, (T)hey can be influenced by politicians, (P)oor salaries can lead to corrupt behaviour, (P)erformance targets can lead to perverse incentives (OECD, 2012 n.p.).

The main thrust of the OECD work in this area is that regulatory inspections play a crucial role in the regulatory governance cycle, inspectorial delivery needs to be based on assessments of risk and evidence, performance should be assessed against clear benchmarks, 'Inspection authorities should be able to clearly demonstrate that they are truly independent from political interference' (OECD, 2012).

This raises a number of questions:

- how do Reviews inform on-going monitoring of Crown Casino in light of the findings of previous Reviews, of legislative changes and the findings of inquiries into gambling and evolving evidence base on the impact of gambling and of gambling operations involved in sale of liquor?

- are the timelines for VCGLR recommendations overly generous, given the issues at stake and the late implementation of well-developed technology such as face recognition, crowd assessment and casino player tracking technologies?

- transparency - will CCM's responses to recommendations from the VCGLR be publicly reported and made public or will the public have to wait until the next Review in 2018 ?

- do the biases and omissions in the Review merit independent audit by the Auditor General or other independent statutory third party with regard to an overhaul of the regulatory process and attention to conflict of interest?

- should the methods of the Review be overhauled, given the questions raised as to the adequacy of the VCGLR routine practices in oversight of RG and RSA at CCM?

\section{Conclusion}

With the NSW State Government giving the go-ahead for a new Crown casino license in Sydney CBD and the Queensland government announcing its consideration of extending its casinos to seven, the issue of social impact of casinos and how they are licensed, monitored, regulated and reviewed, brings up crucial governance, probity and public interest issues. Although governments have expressed a focus on harm minimization and 'responsible gambling', concerns about problem gambling, and (in some States) public health approaches to harm prevention, the dominant prevailing approach is one of individual blame for problem gambling impacts and a lack of focus on governance system surrounding the safety of gambling products (especially electronic gambling machines and automated table games), and the safety of gambling environments characterized by industry selfregulation via unmonitored Codes of Conduct on Responsible Gambling and a lack of emphasis on 
consumer protection from preventable harms related to gambling and gambling environments. Within this mix, gambling regulators tend to focus on tax collection probity, gambling machine pay-outs and perfunctory rule compliance, rather than regulation for safe and sustainable gambling.

Current discourses on 'problem gambling' and 'responsible gambling' are bounded within an individualized informed consumer model, that draws on medicalized typifications of individual pathology. As Bacchi argues, the 'problem gambler paradigm' (demand for gambling) precludes examination of the complex reasons why people gamble and supply factors related to production, packaging and promotion of gambling. It precludes examination of inequitable power relations that underpin gambling-related transactions (Bacchi, 2007 p. 91, 89). Recent research on addiction helpseeking has found that problem gambling is treated as a moral failing, whereas drug or alcohol addiction are regarded more sympathetically than gambling (Jean, 2013). Such typifications of 'the problem' as one of individual weakness divert attention from the responsibility of the State in regulating gambling as a dangerous consumption.

As argued by Gerda Reith (2008, p. 150-151) responsibility is focused on the individual gambler (seen as having freedom and choice) rather than the responsibility of State regulation. This, she argues, reflects the shift under neo liberalism away from production-side issues (supply, availability, accessibility of products) towards the consumption side (individual consumers with choices, freedoms and habits). Similarly, Cosgrave \& Klassen (2009, p. 60) critique 'responsible gambling' as 'neo liberal individualism used rhetorically to obscure the reality of industry (and governments') priority on profit maximisation'. They argue that 'anyone is at risk of gambling irresponsibly'.

A consumer protection and public health lens exposes the bounded rationality of dominant discourses on 'responsible gambling' as the servant of industry and government profit maximization. Underlying current priorities is a callous acceptance of harm to a predicable but significant group of mainly regular gamblers; who are quite frequently also drawn from some of the most vulnerable groups in the community. This is at the expense of precautionary risk aversion, early prevention, safer products and improved safety within gambling environments; that are now within easy reach for governments with the will to implement.

Governments are beholden to the gambling industry to raise much-needed taxes that contribute substantially to revenue (nationally in Australia at about ten percent of State/Territory revenues and about 12-13 percent in Victoria). When the Regulator is responsible both for day-to-day casino monitoring as well as periodic reviews of the licence, it is to a great extent, relying on its own, rather than third party or independent data, which represents a clear conflict of interest and potential compromise of the Review process. This is clearly in contravention of recent critiques of regulatory enforcement highlighted by the OECD (2012; Monk, 2012; Cary 2012) and of the Victorian Government's own policy as articulated in Improving Governance of Regulators: Principles and Guidelines.

\section{References}

Allen Consulting Group (2009) Casinos and the Australian economy. Melbourne: Australian Gaming Council.

Australian Gambling Council (2002) Current issues related to identifying the problem gambler in the gambling venue. Melbourne: Australian Gambling Council.

Bacchi, C. (2007) Analysing Policy: What's the Problem Represented To Be? Melbourne. Pearson Australia. 
Cary C. (2012), "Measuring regulatory performance: evaluating the impact of Regulation and Regulatory Policy", OECD Expert Paper No. 1, August, available at: www.oecd.org/gov/regulatorypolicy/1_coglianese\%20web.pdf.

Cosgrave, J. (2009) 'Governing the Gambling Citizen: The State, Consumption and Risk', Cosgrave, J. F. and Klassen, T. R. eds. Casino State: Legalized Gambling in Canada. Toronto: University of Toronto Press Inc.

Crown Melbourne Limited (2012) Submission to the Victorian Commission for Gambling and LiquorRegulation by Crown Melbourne Limited - Section 25 Casino Operator and Licence Review, 19October 2012.

De Fina, A. and Georgakopoulou, A. (2008) 'Analysing narratives as practices', Qualitative Research, 8(3): 379-387.

Delfabbro, P. (2008) AGR 4: Australasian Gambling Review Fourth Edition (1992-2008). Adelaide: Independent Gambling Authority

Delfabbro P., Osborn A., Nevile M., Skelt L. and McMillen J. (2007) Identifying Problem Gamblers in Gambling Venues: Final Report, prepared for Gambling Research Australia.

Feldman, S.Skoldberg. K., Brown, R., Horner D. (2004) Making Sense of Stories: A Rhetorical Approach to Narrative Analysis, Journal of Public Administration Research and Theory, Vol. 14, no. 2 , pp. $147-170$

Government of Victoria (2013) Casino Control Act 1991, Version No. 079, No. 47 of 1991. Version incorporating amendments as at 15 September 2013. Melbourne: Parliamentary Government Printer.

'Government of Victoria (2013) Casino (Management Agreement) Act 1993 (Vic). Melbourne: Parliamentary Government Printer, Version incorporating amendments as at 15 September 2013. Melbourne: Parliamentary Government Printer..

Government of Victoria (2010), Improving Governance of Regulators: Principles and guidelines. Victoria, Australia: Department of Premier and Cabinet.

Hancock, L. (2011) Regulatory Failure: The case of Crown Casino. Melbourne: Australian Scholarly Publishing.

Hancock, L., Schellinck, T. \& Schrans, T., (2008) 'Gambling and corporate social responsibility (CSR): Re-defining industry and state roles on duty of care, host responsibility and risk management', Policy and Society, 27, pp. 55-67.

Jean, P. (2013) ‘Gamblers blamed for addiction', The Age. November 17.

Livingstone, C. (2013) 'Responsible gambling and the spectacle of the 'problem gambler', The Conversation, 26 April.

Livingstone, C. \& Woolley, R. (2007). 'Risky business: A few provocations on the regulation of electronic gaming machines', International Gambling Studies, 7(3), pp. 361-376.

May V. (n.d.) What is... Narrative Analysis? Realities (Part of the ESRC National Centre for Research Methods) Accessed October 21 at:

http://www.methods.manchester.ac.uk/events/whatis/narrativeanalysis.pdf 
May, Vanessa (2008) 'On being a 'good' mother: The moral presentation of self', Sociology, 42: 470-486.

McBeth, Mark K., Shanahan, Elizabeth A. \& Jones, Michael D. (2005) 'The science of storytelling: Measuring policy beliefs in Greater Yellowstone', Society \& Natural Resources, 18(5): 413-429

Macreadie, R. (2009) 'Casino Legislation Amendment Bill 2009', Research Brief No. 5, Parliamentary Library Research Services. Melbourne: Parliament of Victoria.

Monk, (2012) Reform of Regulatory Enforcement and Inspections in OECD Countries. Paris, OECD.

Needham, K. (2013) 'Outrage as casino games to be rolled out across suburbia' Sydney Morning Herald, 12 May.

Nichols, S. (2013) ‘\$1.3b gamble pays off’, Sydney Morning Herald, July 5.

OECD \& European Commission (2009), "Better Regulation in Europe: An assessment of regulatory capacity in 15 member states of the European Union - Better Regulation in the Netherlands", available on line at: www.oecd.org/regreform/regulatorypolicy/43307757.pdf.

OECD (2011), "Report: Internal Control \& Internal Audit: Ensuring public sector integrity and Accountability OECD", available at: www.oecd.org/governance/47638204.pdf

OECD (2012) OECD Workshop on Regulatory Enforcement \& Inspection, hosted by the Israeli Government. Jerusalem: October 29-30. Accessed September 22013 at: http://www.oecd.org/gov/regulatory-policy/regulatoryenforcementandinspections.htm

Pedriana, Nicholas (2006) 'From protective to equal treatment: Legal framing processes and transformation of the women's movement in the 1960s', American Journal of Sociology, 111(6): $1718-61$.

Public Health Association of Australia (2010) Gambling Industry Funding Policy. Accessed on September 1, 2013 at: http://www.phaa.net.au/documents/policy/101216_Gambling\%20Industry\%20Funding\%20Policy. pdf

Reith G. (2008) 'Reflections on Responsibility', Journal of Gambling Issues, 22, p. 149-155. Responsible Gambling Foundation (n.d.) Guide to Responsible Gambling. North Melbourne: Responsible Gambling Foundation.

Riessman, Catherine Kohler (2008) Narrative Methods for the Human Sciences, Los Angeles, CA: Sage.

Schellinck T. and Schrans T., 2011, Intelligent design: How to model gambler risk assessment by using loyalty tracking data. Journal of Gambling Issues: Issue 26, pp. 51-68.

Smith, G. 2012. 'Review: Regulatory Failure: The Case of Crown Casino', Australian Journal of Political Science, 47 (2): 319-320.

Squire, C., Andrews, M. \& Tamboukou, M. (2008) 'Introduction: What is narrative research?' in Andrews, M., Squire, C. \& Tamboukou, M. (eds), Doing Narrative Research. London: Sage.

The Australian (2012) 'Wilke drops support for Gillard after pokies backflip', National Affairs. The Australian, January 22 Accessed September 29 at: www.theaustralian.com.au/...wilkies.../storyfn59niix-1226250124066 
University of Manchester(2013) Narrative analysis: Methods @ Manchester: research methods in the social sciences. Accessed October 202013 at:

http://www.methods.manchester.ac.uk/methods/narrative/

Victorian Casino and Gambling Authority (VCGA) (1997) First Triennial Review of the Casino Operator and Licence, Melbourne: VCGA.

Victorian Casino and Gambling Authority (VCGA) (2000) Second Triennial Review of the Casino Operator and Licence. Melbourne: VCGA.

Victorian Casino and Gambling Authority (VCGA) (2003) Third Triennial Review of the Casino Operator and Licence. Melbourne: VCGA.

Victorian Commission for Gambling and Liquor Regulation (VCGLR) (2013) Fifth Review of the Casino Operator and Licence, June. Melbourne: VCGLR

Victorian Commission for Gambling and Liquor Regulation (VCGLR) (2013b) 'Review of Crown Casino licence released', Media Release. Wednesday 14 August. Melbourne: VCGLR.

Victorian Commission for Gambling Regulation (VCGR) (2008) Fourth Review of the Casino Operator and Licence, June. Melbourne: VCGR.

Victorian Commission for Gambling Regulation (VCGR) (2009) Ministerial Direction: Responsible Gambling Codes of Conduct, Gambling Regulation Act 2003. Accessed at http://www.vcgr.vic.gov.au/CA256F800017E8D4/Legal/392991D99D9EE300CA2574D600020E 9D?Open 
